\title{
Health-related benefits among children in the child welfare system: prevalence and determinants of basic and/or attendance benefits
}

\author{
Abreham Mengesha Zewdu \\ Norwegian Social Research (NOVA), P.O. Box 3223 Elisenberg, N-0208 Oslo, Norway \\ E-mail: abrehamm@hotmail.com Telephone:+4722541200
}

\begin{abstract}
Objective: To examine the prevalence and determinants of basic and/or attendance benefits among children involved with the child welfare system (CWS).

Design: A register study of all children involved with CWS in Norway from 1997-2006.

Participants: 96,354 children from the CWS group and 149,030 children who had never been in the CWS as a comparison group.

Results: $11 \%$ of children involved with CWS received basic and/or attendance benefits compared to $3 \%$ in the comparison group. In multivariate logistic regression, the boys' chances of ever receiving basic and/or attendance benefits were greater than the girls' chances. The chances of receiving benefits increased nearly four to sixfold as a child becomes older. However, they decrease as the age at debut to CWS increases. It was also revealed that those children who stayed under child welfare for two or more years had an increased chance of ever receiving basic and/or attendance benefits. For children with reported behavioral disorders, the chances of basic and/or attendance benefits were nearly twofold. For children under home-based support and medication interventions, the chances of receiving basic and/or attendance benefits were greater than for children who were not under these interventions.

Conclusion: Chronic health conditions that claim basic and/or attendance benefits were more prevalent among children involved with CWS than the general children's population. This phenomenon may be explained by gender, age, age at debut to CWS, length of stay under CWS, types and reasons for interventions.
\end{abstract}

During the past 10 years, nearly 100,000 children were involved with the child welfare system (CWS) in Norway. Each year, more than 30,000 children were assisted and over 8,000 new children were placed under the auspices of child welfare protection. During the same period, the number of children in care grew from 29,500 in 1997 to 40,213 in 2006, an increase of $36 \%$ (Statistics Norway, 2009). This growth may be attributed in part to a change in the regulation and reporting system, and in part to an increase in needy children and the capacity of the CWS (Clausen and Kristofersen, 2008).

The circumstances that force children into the CWS are an adverse experience which may have a long-term negative health outcome (Takayama et al., 1998; Dube et al., 2001; Dubowitz et al., 2002; Felitti, 2002; Leslie et al., 2003; Flaherty et al., 2006; Wang and Holton et al., 2007; Springer et al., 2007). When compared with the general population of children, those under the CWS are more likely to have physical and mental health problems (Farmer et al., 2001; Green et al., 2005; Hill and Thompson, 2003; Kortenkamp and Ehrle, 2002). Research findings in the US revealed that at least one chronic condition was present in the majority of children entering foster care (Steele and Buchi, 2008; Leslie et al., 2005; Chernoff et al., 1994). The most widely reported chronic health problems among CWS children are obesity, asthma, bronchitis, hyper- tension, ulcer, vision problems, hearing problems, malnutrition, physical injuries, emotional problems and conduct and adjustment disorders (Ringeisen et al., 2008; Steele and Buchi, 2008; Iversen et al., 2007). All these suggest that children under care present challenges to society in general and to child welfare agencies in particular, as they require health care resources and caregivers attention and time (Kortenkamp and Ehrle, 2002; Van Cleave et al., 2010). Moreover, the costs needed to meet the needs of these children should not be underestimated since these costs are associated with the child's immediate health needs as well as those associated with a loss of productivity due to unemployment and under employment later in life (Caldwell, 1992; Fromm, 2001; Wang and Holton, 2007).

We do not have sufficient data to ascertain the health status of each child involved with CWS in Norway, so instead we use health-related services such as basic and/or attendance benefits to infer this status. According to the National Insurance Act, children eligible for basic and/or attendance benefits are those with: 1) a health condition characterized by chronic illness, injury or an impairment that limits their activities over a given period of time, 2) a health condition characterized by huge extra costs associated with medication and special services over a given period of time (Folketrygdloven §6). A previous study by Kristofersen (2005) reported that a larger proportion of 
children involved with CWS received basic and/or attendance benefits in comparison to their peers from the general population. Still, the determinants of basic and/or attendance claims have not been well studied, which is the overall purpose of this study that intends to answer two specific questions:

1. How prevalent are basic and/or attendance benefits in children involved with CWS when compared with their peers from the general population?

2. To what extent can basic and/or attendance benefits among CWS children be explained by socio-demographic and child welfare-related characteristics?

\section{METHODS AND MATERIAL}

This study is part of an ongoing longitudinal research project on CWS children conducted from 1990 through 2011 and is currently financed by the Norwegian Directorate for Children, Youth and Family Affairs. Data were obtained through the linking of several national registries from Statistics Norway (SSB). The variables included were gender, age, age at debut to CWS, child's country of origin, mother's income, mother's education, reason for child welfare intervention, type of child welfare intervention, length of stay under child welfare and receipt of basic and/or attendance benefits.

\section{Study population}

We included all children who were in contact with CWS and were provided home and/or institutionally based services from 1997 through 2006. Our data set included children who were under child welfare protection during the study period as well as children and young adults who left CWS because they either no longer needed child welfare protection or they were beyond the age limit. We also included randomly selected children from the general population who were never involved with CWS as a comparison group. Both groups were fairly matched in terms of demographic and socio-economic characteristics. A total of 245,384 (96,354 from the CWS group and 149,030 from the comparison group) were included.

\section{Measures}

Demographic and socio-economic characteristics The demographic and socio-economic characteristics of the study population were taken from the SSB registry and consisted of the following variables:

$>$ Gender

$>$ Age: age of the study population in 2006 and reported on a four-point scale ranging from " $0-5$ " to " $\geq 18$ ".

$>$ Age at debut: the age at which a child was registered as a client by child welfare agency for the first time and reported on a three-point scale ranging from " $0-5$ " to " $13-17 . "$

$>$ Length of stay under CWS: the period of time a child stayed under CWS expressed in a calendar year. Any length of stay in a given year was considered as one full calendar year.

$>$ Country of origin: children's country/region of origin was determined by parents' country/region of birth. In case parents had different country/region of birth, mother's country/region of birth was taken as a reference.

$>$ Mother's income: mother's annual net income in Norwegian kroner (NOK) reported on a five-point scale ranging from " $<100,000$ " to " $>400,000$."

> Mothers' education: mother's completed level of education reported on a three-point scale ranging from "junior secondary school" to "tertiary level" of education. Variables pertaining to the father's income and education were left out because of too much missing data.

\section{Reasons and types of intervention}

Statistics Norway recorded 13 reasons and 25 types of CWS interventions. Nevertheless, using a factor analysis technique, we reduced the reasons for interventions into the following main variables:

Neglect: included if a child was subjected to a parent's reported inability to properly care for the child, a parent's abuse of intoxicants and/or a parent's mental suffering.

$>$ Abuse: included if a child was reported to have experienced any type of sexual, mental and/or physical abuse.

> Behavioral disorder: included if a child was reported to have experienced a deviant behavior and/or abuse of intoxicants.

$>$ Conditions in the home: included if there were reports of unfavorable conditions in the home environment and/or disability of the child.

Concomitantly, we reduced the types of intervention into five core variables:

Support: included if a child received supportive contact, a home visit, leisure activities, financial support, day care facilities, supervision, in-home respite and/or housing/lodging.

$>$ Foster home placement: included if a child was placed under foster home care outside the family, foster home within the family and/or reinforced foster homes.

> Institutional placement: included if a child was placed under child welfare institutions, emergency shelter home, children's home, institute for drug addicts and/or child and youth psychiatric institution.

$>$ Medication: included if a child received medical examination /treatment, special needs treatment and/or psychiatric treatment.

\section{Basic and attendance benefits}

In Norway, basic and attendance benefits are part of the national insurance scheme for people with longterm diseases, injuries or impairments and are defined as follows: 
Table 1. Basic and/or attendance benefits receipt by socio-demographic characteristics.

\begin{tabular}{|c|c|c|c|c|}
\hline \multirow[b]{3}{*}{ Variables } & \multicolumn{4}{|c|}{ Basic and/or attendance benefits } \\
\hline & \multicolumn{2}{|c|}{ CWS children $=10,814(11 \%)$} & \multicolumn{2}{|c|}{ Non-CWS Children $=4,974(3 \%)$} \\
\hline & $\%$ & $\mathrm{~N}$ & $\%$ & $\mathrm{~N}$ \\
\hline \multicolumn{5}{|l|}{ Gender } \\
\hline Male & 14.0 & 7296 & 4.0 & 3004 \\
\hline Female & 8.0 & 3513 & 3.0 & 1970 \\
\hline \multicolumn{5}{|l|}{ Age category (2006) } \\
\hline$\leq 5$ & 2.0 & 214 & 1.0 & 131 \\
\hline $6-12$ & 9.0 & 2504 & 4.0 & 1163 \\
\hline $13-17$ & 15.0 & 3915 & 5.0 & 1608 \\
\hline $18+$ & 12.0 & 4176 & 3.0 & 2072 \\
\hline \multicolumn{5}{|l|}{ Child's country of origin } \\
\hline Norway & 13.0 & 8909 & 4.0 & 4311 \\
\hline Europe \& North America & 10.0 & 753 & 2.0 & 286 \\
\hline Africa, Asia \& Latin America & 6.0 & 1077 & 3.0 & 349 \\
\hline \multicolumn{5}{|l|}{ Mother's net income in NOK } \\
\hline$\leq 100,000$ & 9.0 & 813 & 3.0 & 386 \\
\hline $101,000-200,000$ & 12.0 & 4188 & 4.0 & 1612 \\
\hline $201,000-300,000$ & 12.0 & 4291 & 4.0 & 2190 \\
\hline $301,000-400,000$ & 11.0 & 972 & 4.0 & 551 \\
\hline$\geq 401,000$ & 9.0 & 123 & 3.0 & 148 \\
\hline \multicolumn{5}{|l|}{ Mother's education } \\
\hline Elementary \& junior secondary school & 14.0 & 3848 & 4.0 & 939 \\
\hline Upper secondary high school & 15.0 & 2413 & 4.0 & 1416 \\
\hline University education & 14.0 & 785 & 4.0 & 907 \\
\hline Unknown & 8.0 & 3768 & 3.0 & 1712 \\
\hline
\end{tabular}

\section{Basic benefits}

Basic benefits are economic compensation given by the national insurance scheme to a parent/primary caregiver for significant extra expenses due to a child having a prolonged impairment of mental and/or physical functions (Folketrygdloven $\S 6$ ). These benefits are intended to cover extra costs due to the need for one or more of the following: technical aid apparatus, special transport, guide dog, telephone/other essential electronic communication aids, prostheses/support bandages, special diet (when prescribed by a physician) and adequate clothing. There are six basic benefit rates that are adjusted by the parliament one or more times a year. The annual rates in 2006 varied from NOK 16,540 to NOK 32,748 .

\section{Attendance benefits}

Attendance benefits are an economic compensation given by the national insurance scheme to parents/primary caregivers in order to compensate for an economic loss due to time spent on providing extra care for a child who has a prolonged impairment of mental and/or physical functions (Folketrygdloven §6). An attendance benefit is granted if the affected child needs special attention or nursing. There are four rates which are adjusted by the parliament one or more times a year. The annual rate in 2006 varied from NOK 11,724 to NOK 70,344 with the highest rate only granted to children under the age of 18 . Children involved with CWS who continuously/intermittently receive basic and/or attendance benefits considered to be children with chronic health problems.

\section{Method of analysis}

Data were analyzed by means of contingency tables and descriptive statistics. The determinants of basic and/or attendance benefits (dependent variables) were analyzed using logistic regression. Data were analyzed using SPSS version 17.

\section{RESUlts}

We assessed the prevalence of basic and/or attendance benefits among CWS involved children and compared them with children who have never been involved with CWS in terms of gender, age, children's country of origin and mother's income and education. We also assessed basic and/or attendance benefits in CWS children across age at debut, length of stay under CWS, reasons for and types of CWS interventions. Our findings revealed that $11 \%$ of children involved with CWS have received basic and/or attendance benefits on either a continuous or an intermittent basis. The corresponding proportion for the comparison group was only $3 \%$ (Table 1 ).

\section{Gender and age}

The prevalence of basic and/or attendance benefits across gender and age groups is shown in Table 1. Of the CWS group, the prevalence of basic and/or attendance 
benefits was higher among male than female children (14\% vs. $8 \%$ ). Fifteen percent of children aged 13 to $17,9 \%$ of children aged 6 to 12 and $2 \%$ of children under the age of 6 were basic and/or attendance benefits recipients, while $12 \%$ of recipients were over the age of 18 . In all age groups, male children were more likely to receive basic and/or attendance benefits compared with females. Similar patterns of variations were also observed across gender and age in the comparison group.

\section{Child's country of origin}

Table 1 shows that the prevalence of basic and/or attendance benefits receipt was more than double for children of Norwegian origin than for children from Africa, Asia and Latin American combined (13\% vs. $6 \%$ ). Not much variation was observed in the comparison group.

\section{Mother's income and education}

Table 1 shows the prevalence of basic and/or attendance benefits by the mother's income and education levels. Of the CWS involved children who received benefits, the vast majority had mothers with an annual income of NOK 100,000 to 300,000 (24\%). Children who had a mother with an income of either less than NOK 100,000 or more than NOK 400,000 (18\%) received a relatively lower proportion of benefits. However, the general trend was that basic and/or attendance benefits decreased as the mother's income increased. No major variations were observed in the prevalence of a child's basic and/or attendance benefits according to the mother's education: primary and junior high school (14\%), upper high school (15\%) and university education (14\%). Similar patterns of variations in basic and/or attendance benefits were observed across mothers' income and education levels for the comparison group.

\section{Age at debut}

Table 2 summarizes the prevalence of basic and/or attendance benefits with characteristics unique to children under protection. Accordingly, the prevalence of basic and/or attendance benefits varied slightly from $13 \%$ for children who debuted with CWS between the ages of 6 to 12 to $9 \%$ for children who debuted with CWS under the age of 6 .

\section{Length of stay under child welfare}

The prevalence of basic and/or attendance benefits varied significantly across the length of stay, ranging from $8 \%$ for those who stayed under CWS for 1 year to $20 \%$ for those who stayed under CWS for at least 10 years.

\section{Basic and/or attendance benefits by reason for $\mathrm{CWS}$ intervention}

Our findings revealed that the main reasons for children to be involved with CWS were conditions in the home (62\%), neglect (40\%) and behavioral disorders $(26 \%)$. Significant proportions of these children were also likely to receive basic and/or attendance benefits, with $18 \%$ due to reported behavioral disorders, $13 \%$ due to conditions in the home and $11 \%$ due to neglect (Table 2). We found that the total number of children under 'reason for child welfare intervention' was far greater than the total number of children who received basic and/or attendance benefits. This may suggest that a child could be contacted by child welfare authorities for multiple reasons.

\section{Basic and/or attendance benefits by intervention type}

Our research revealed that $18 \%$ of children under medication, $12 \%$ of children under various types of home-based support and $12 \%$ of children under institutional placement were receiving basic and/or attendance benefits (Table 2). It was also found that the number of children under 'types of interventions' was far greater than the total number of children who received basic and/or attendance benefits. This may suggest that some children could be placed under multiple interventions.

Table 2. Basic and/or attendance benefits recipients by debut age, length of stay, reason and type of intervention.

\begin{tabular}{|c|c|c|}
\hline & \multicolumn{2}{|c|}{$\begin{array}{c}\text { Basic and/or } \\
\text { attendance benefits }\end{array}$} \\
\hline & $\%$ & $\mathrm{~N}$ \\
\hline \multicolumn{3}{|l|}{ Age at debut to child welfare } \\
\hline $0-5$ & 10.0 & 3852 \\
\hline $6-12$ & 13.0 & 3998 \\
\hline $13-17$ & 9.0 & 2003 \\
\hline \multicolumn{3}{|c|}{ Length of stay under child welfare } \\
\hline One year & 8.0 & 1902 \\
\hline Two years & 9.0 & 1984 \\
\hline Three years & 10.0 & 1439 \\
\hline Four years & 11.0 & 1129 \\
\hline Five years & 13.0 & 977 \\
\hline Six years & 16.0 & 840 \\
\hline Seven years & 16.0 & 659 \\
\hline Eight years & 17.0 & 524 \\
\hline Nine Years & 17.0 & 468 \\
\hline Ten Years & 20.0 & 892 \\
\hline \multicolumn{3}{|l|}{ Reasons for intervention } \\
\hline Neglect & 11.0 & 4273 \\
\hline Abuse & 11.0 & 779 \\
\hline Behavioral disorder & 18.0 & 4508 \\
\hline Conditions in the home & 13.0 & 7707 \\
\hline \multicolumn{3}{|l|}{ Types of intervention } \\
\hline Support & 12.0 & 9592 \\
\hline Foster home placement & 12.0 & 2227 \\
\hline Institutional placement & 12.0 & 2361 \\
\hline Medication & 18.0 & 1702 \\
\hline Other & 13.0 & 7142 \\
\hline
\end{tabular}


Table 3. Multivariate logistic regression analysis of ever receiving basic and/or attendance benefits.

\begin{tabular}{|c|c|c|c|c|c|}
\hline \multirow[b]{2}{*}{ Selected variables } & & \multicolumn{4}{|c|}{$\begin{array}{c}\text { Basic and/or attendance benefits } \\
95 \% \text { confidence interval }(\mathrm{CI}) \text { for odds ratio ( OR) }\end{array}$} \\
\hline & & OR & Lower & Upper & Sig \\
\hline \multicolumn{6}{|l|}{ Demographics } \\
\hline \multirow[t]{2}{*}{ Gender } & Male & 1.0 & & & \\
\hline & Female & .55 & .53 & .58 & .000 \\
\hline \multirow[t]{4}{*}{ Age } & $0-5$ & 1.0 & & & \\
\hline & $6-12$ & 3.80 & 3.29 & 4.40 & .000 \\
\hline & $13-17$ & 6.10 & 5.21 & 7.16 & .000 \\
\hline & $18+$ & 4.98 & 4.20 & 5.91 & .000 \\
\hline \multirow[t]{3}{*}{ Age at debut } & $0-5$ & 1.0 & & & \\
\hline & $6-12$ & .85 & .81 & .90 & .000 \\
\hline & $13-17$ & .49 & .45 & .53 & .000 \\
\hline \multicolumn{6}{|l|}{ Socio-economic variables } \\
\hline \multirow[t]{3}{*}{ Child's country of origin } & Norway & 1.0 & & & \\
\hline & Europe and N. America & .76 & .70 & .83 & .000 \\
\hline & Africa, Asia \& L. America & .55 & .52 & .60 & .000 \\
\hline \multirow[t]{5}{*}{ Mother's net income in NOK } & $<100,000$ & 1.0 & & & \\
\hline & $101,000-200,000$ & 1.11 & 1.01 & 1.21 & .025 \\
\hline & $201,000-300,000$ & 1.14 & 1.04 & 1.24 & .004 \\
\hline & $301,000-400,000$ & 1.01 & .91 & 1.12 & .870 \\
\hline & $>401,000$ & .81 & .66 & .99 & .048 \\
\hline \multirow[t]{3}{*}{ Mothers' education } & Junior secondary & 1.0 & & & \\
\hline & upper secondary & 1.05 & .99 & 1.12 & .093 \\
\hline & Tertiary level & 1.11 & 1.01 & 1.22 & .031 \\
\hline \multirow[t]{2}{*}{ Length of stay under welfare } & One year & 1.0 & & & \\
\hline & Two or more years & 1.18 & 1.11 & 1.25 & .000 \\
\hline \multicolumn{6}{|l|}{ Reason for intervention } \\
\hline \multirow[t]{2}{*}{ Neglect } & No & 1.0 & & & \\
\hline & Yes & .71 & .68 & .75 & .000 \\
\hline \multirow[t]{2}{*}{ Abuse } & No & 1.0 & & & \\
\hline & Yes & .95 & .86 & 1.03 & .223 \\
\hline \multirow[t]{2}{*}{ Behavioral disorder } & No & 1.0 & & & \\
\hline & Yes & 1.88 & 1.78 & 1.97 & .000 \\
\hline \multirow[t]{2}{*}{ Conditions in the home } & No & 1.0 & & & \\
\hline & Yes & 1.27 & 1.20 & 1.33 & .000 \\
\hline \multicolumn{6}{|l|}{ Types of intervention } \\
\hline \multirow[t]{2}{*}{ Support } & No & 1.0 & & & \\
\hline & Yes & 1.38 & 1.29 & 1.48 & .000 \\
\hline \multirow[t]{2}{*}{ Institutional placement } & No & 1.0 & & & \\
\hline & Yes & .98 & .93 & 1.05 & .620 \\
\hline \multirow[t]{2}{*}{ Foster home placement } & No & 1.0 & & & \\
\hline & Yes & 1.03 & .96 & 1.11 & .372 \\
\hline \multirow[t]{2}{*}{ Medication } & No & 1.0 & & & \\
\hline & Yes & 1.16 & 1.09 & 1.24 & .000 \\
\hline
\end{tabular}

\section{Statistical model predicting basic and/or attendance benefits}

Table 3 reports multiple regression models capturing the associations of children's gender, age, age at debut to CWS, country of origin, length of stay under CWS, reasons for involvement in CWS, types of interventions and mother's income and education with regard to ever receiving basic and/or attendance benefits. Our analysis revealed that gender, age, age at debut to
CWS, children's country of origin and length of stay under welfare were significantly associated with ever having received basic and/or attendance benefits. Girls' chances of ever receiving basic and/or attendance benefits were less than the boys' chances.

The chance of receiving benefits increased nearly four to sixfold as a child becomes older. However, the chance of receiving benefits decreases as the age at debut to CWS increases and we found that children of 
Norwegian origin were more likely to receive basic and/or attendance benefits compared with children of non-Norwegian origin. Our findings also revealed that those children who stayed under child welfare for two or more years had an increased chance of ever receiving basic and/or attendance benefits.

We also assessed the associations between reasons and types of child welfare intervention with regard to ever having received basic and/or attendance benefits. Children contacted by child welfare agencies due to reported neglect had less chance of ever receiving basic and/or attendance benefits. However, for children with reported behavioral disorders, the chances of basic and/or attendance benefits were nearly twofold. For those children contacted by child welfare agencies due to reported conditions in the home, the chances of ever receiving benefits were greater, while for children under home-based support and medication the chances of receiving basic and/or attendance benefits were greater than for children who were not under these interventions.

\section{DISCUSSION}

This study demonstrated that a significant proportion of children involved with CWS received basic and/or attendance benefits compared with their peers from within the general children's population and that the likelihood of ever receiving basic and/or attendance benefits is nearly four times higher for children involved with CWS. This may suggest that receiving services is an indirect indication of chronic health problems among CWS children (Kortenkamp and Ehrle, 2002, Hjern et al., 2003, Simms et al., 2000). Nonetheless, the proportion varies across demographic, socioeconomic and child welfare characteristics. Our study revealed that a larger proportion of boys received basic and/or attendance benefits than girls, which is in line with previous studies that boys were more associated with chronic health problems (Ringeisen et al., 2008). Even so, our findings do seem to contradict the figure for the entire population of Norway since according to national statistics from 2006, a larger proportion of basic and/or attendance benefits recipients was female (Department of Labor, 2006). Our findings also documented a strong association between age and basic and/or attendance benefits receipt. The largest proportion of children who received basic and/or attendance benefits was adolescents, which was in accordance with a previous study by Kristofersen (2005). Moreover, findings that basic and/or attendance benefits receipt for those aged $\geq 18$ was six times higher for children involved with CWS than the general children's population strengthened previous research that an adverse childhood experience has a long lasting negative health effect (Flaherty et al., 2006; Dube et al., 2001). However, a debut to CWS at an early age did not decrease the likelihood of receiving basic and/or attendance benefits, though this finding stands in con- trast to a previous study that early intervention is likely to bring a better long-term outcome (Fisher et al., 2005). Nonetheless, children who stayed longer in the CWS were more likely to receive basic and/or attendance benefits. These results strengthen previous findings that the longer a child stayed under welfare, the higher the likelihood of receiving basic and/or attendance benefits (Kristofersen, 2005). The results of our study demonstrated that the receipt of basic and/or attendance benefits could not be explained by the mother's poor income and level of education. Children with middle-income mothers were more likely to receive basic and/or attendance benefits as compared with children of low- and high-income mothers. While having a high income may be self-explanatory, the findings with low-income mothers may appear to be at odds with the conventional wisdom that children from poor income families are presumed to be more susceptible to chronic health conditions that may lead to basic and/or attendance benefits claims. These findings support similar previous findings that a poor socioeconomic condition could not explain a child's mental health problems (Iversen et al., 2007). One possible explanation could be that poor income families may already be involved with the social welfare system so that their children's needs were duly identified and met, although an alternative explanation could be that the poorest children's needs were not identified by CWS intervention. The fact that most children who received basic and/or attendance benefits were of Norwegian origin may not necessarily suggest that Norwegian children were at an exceptionally higher risk of chronic health conditions. Instead, this could be due to the fact that children of Norwegian origin have better informational access to child welfare or that $73 \%$ of children involved with CWS were of Norwegian origin. Our findings also demonstrated that a larger proportion of children who received basic and/or attendance benefits were children who contacted CWS due to reported behavioral disorders, as our regression analysis also showed a strong statistical association with this aspect. This may further explain why male adolescent children were more likely to receive basic and/or attendance benefits than their female counterparts (Kristofersen, 2005). Reports of abuse did not predict the basic and/or attendance benefits outcome, which could be due to the fact that children either outgrow the problem or the conditions appear to be absent for a longer period before reoccurring again in midlife (Van Cleave et al., 2010). An alternative explanation could be due to under reporting since very young children may be incapable of verbally communicating the harm inflicted on them. Additional factors such as fear, guilt, or confusion about the abuser's behavior may also hinder younger children from reporting their abuse.

Our research also examines the link between basic and/or attendance benefits and type of CWS intervention. A CWS intervention is intended to improve the 
child's home environment in order to safeguard them from physical and/or psychological harm so that any potential or actual cause of child stress will not have any long-term impact, with most interventions having that exact effect. Yet, we found certain interventions were likely to be associated with basic and/or attendance benefits claims. In our study, children under medication and several home-based support programs were most likely to receive basic and/or attendance benefits. This may warrant further investigation, we suspect that this could be due to children placed under medical interventions reflect the traumatic experiences they had before the interventions, or some interventions may not be enough, ill-timed or inappropriate at all.

Our study has strengths as well as limitations. One of its strengths is our methodology, as we included all children involved with CWS from 1997 through 2006. We believed that by doing this we would minimize the effect of bias that might be raised due to sampling. Still, our research is not without its limitations, such as a lack of individual health data. We relied on officially registered data that was devoid of any sensitive health information. Our findings may suggest the degree of chronic health problems, but cannot tell us about specific health problems responsible for basic and/or attendance benefit claims. We also felt that qualitative information obtained through interviews with the affected children, parents, child welfare agents and health personnel could have provided our research with a more in-depth insight.

Despite its limitations, our research had both practical and policy implications. The fact that the preva- lence of basic and/or attendance benefits was nearly four times higher for CWS children than for the general population of children clearly implies a higher risk for chronic health conditions associated with CWS children. Our findings only included those children who qualified for basic and/or attendance benefits according to the level of their ill health, injuries and associated high costs. Children with chronic conditions who did not incur any additional costs, as well as chronic conditions which might qualify but were not reported to national insurance agencies, were not included. This may suggest that the health problems of children under protection are wider and more serious than what is reported here. The fact that the children most affected were adolescent males may suggest a need to have gender- and age-specific intervention strategies. In addition, a periodic evaluation to measure the effectiveness of intervention strategies should be undertaken. Finally, attempts should be made to find a durable solution that takes children out of CWS in the shortest amount of time. By doing so, it is possible to minimize the risk of chronic conditions that may arise due to a prolonged stay.

Our research demonstrated that chronic health conditions which claim basic and/or attendance benefits were more prevalent among children involved with CWS than the general population of children. This phenomenon seems to be associated with gender, age, length of stay under CWS, and reasons and types of interventions. Further research is needed to examine the link between children involved with CWS and specific health problems and appropriate intervention strategies.

\section{REFERENCES}

Caldwell RA. The costs of child abuse vs. child abuse prevention: Michigan's experience. 1992 [cited Feb 17, 2010]. Available from: https: //www.msu.edu/user/bob/cost.html.

Chernoff R, Combs-Orme T, Riseley-Curtiss C, Heisler A. Assessing the health of children entering foster care. Pediatrics 1994; 93: 594-601.

Clausen S-E, Kristofersen LB [Norwegian Child Welfare Clients 1990-2005. A longitudinal study]. Norwegian Social Research (NOVA) 2008; NOVA Rapport No 3.

Department of Labor [Basic and attendance benefits]. 2006 [cited Feb 22, 2010]. Available from: http://www. regjeringen.no/nb/dep/ad/dok/regpubl/stprp/200620077stprp-nr-1-2006-20.

Dube SR, Anda RF, Felitti VJ, Chapman DP, Williamson DF, Giles WH. Childhood abuse, household dysfunction, and the risk of attempted suicide throughout the life span: Findings from the Adverse Childhood Experiences Study. JAMA 2001; 286 (24): 3126-7.

Dubowitz H, Papas MA, Black MM, Starr RH Jr. Child neglect: outcomes in high-risk urban preschoolers. Pediatrics 2002; 109: 1100-7.

Farmer EMZ, Burns BJ, Chapman MV, Phillips SD, Angold A, Costello EJ. Use of mental health services by youth in contact with social services. Soc Service Rev 2001; 75: 605-24.

Felitti VJ. The relationship of adverse childhood experiences to adult health: turning gold into lead (Translated from German into English). Z Psychosom Med Psychother 2002; 48 (4): 359-69.

Fisher PA, Burraston B, Pears K. The Early Intervention Foster Care Program: Permanent placement outcomes from a randomized trial. Child Maltreat 2005; 10: 61-71.

Flaherty EG, Thompson R, Litrownik AJ, Theodore A, English DJ, Black MM. Effect of early childhood adversity on child health. Arch Pediatr Adolesc Med 2006; 160: 1232-8. 
Folketrygdloven [National Insurance Act of 1997] §6-4 and 6-5. Available from http/www.lovdata.no/all/tl19970228-019-018.html.

Fromm S. The total cost of child abuse and neglect in the United States. Statistical evidence. Prevent Child Abuse America. 2001; Funded by The Edna McConnell Clark Foundation.

Green R, Sommers A, Cohen M. Medical spending on foster children. The Urban Institute 2005; Brief No. 2.

Hill C, Thompson M. Mental and physical health co-morbidity in looked after children. Clin Child Psychol Psychiatry 2003; 8 (3): 315-32.

Hjern A, Vinnerljung B, Lindblad F. Avoidable mortality among child welfare recipients and intercountry adoptees: a national cohort study. J Epidemiology Community Health 2003; 58: 412-7.

Horwitz SM, Owens P, Simms MD. Specialized assessments for children in foster care. Pediatrics 2000; 106: 5966.

Iversen AC, Jakobsen R, Havik T, Hysing M, Stormark KM. Mental health problems among child welfare clients living at home. Child Care Pract 2007; 13: 387-99.

Kortenkamp K, Ehrle J. The well-being of children involved with the child welfare system: a national overview. The Urban Institute Series 2002; No. B-43.

Kristofersen LB. Barnevernet helse: uførhet og dødelighet i perioden 1990-2002 [Health Status of Children in Care. Disability and Mortality, 1990-2002]. Oslo: Norsk Institutt for by-og regionforskning (NIBR) 2005; Report No. 12.

Leslie LK, Gordon JN, Meneken L, Premji K, Michelmore KL, Ganger W. The physical, developmental, and mental health needs of young children in child welfare by initial placement type. J Dev Behav Pediatr $2005 ; 26$ (3): 177-85.

Leslie LK, Hurlburt MS, Landsverk J, Rolls JA, Wood PA, Kelleher KJ. Comprehensive assessments for children entering foster care: A national perspective. Pediatrics 2003; 112: 134-42.

Ringeisen H, Casanueva C, Urato M, Cross T. Special health care needs among children in the child welfare system. Pediatrics 2008; 122: e232-e241.

Simms MD, Dubowitz H, Szilagyi MA. Health care needs of children in the foster care system. Pediatrics 2000; 106: 909-18.

Springer KW, Sheridan J, Kuo D, Carnes M. Long-term physical and mental health consequences of childhood physical abuse: Results from a large population-based sample of men and women. Child Abuse Neglect 2007; 31: $517-30$.

Statistics Norway. Child Welfare. 2009 [Cited Feb 6, 2010]. Available from http//www.ssb.no/barneverng_en/tab2009-07-06-03-en.html.

Steele JS, Buchi KF. Medical and mental health of children entering the utah foster care system. Pediatrics 2002; 22: e703-e709.

Takayama JI, Wolfe E, Coulter KP. Relationship between reason for placement and medical findings among children in foster care. Pediatrics 1998; 101: 201-7.

Van Cleave J, Gortmaker SL, Perrin JM. Dynamics of obesity and chronic health conditions among children and youth. JAMA 2010; 303: 623-30.

Wang C-T, Holton J. Total estimated cost of child abuse and neglect in the United States. Prevent Child Abuse America 2007; Funded by the Pew Charitable Trust. 